\title{
School Violence, Depressive Symptoms, and Help-seeking Behavior: A Gender-stratified Analysis of Biethnic Adolescents in South Korea
}

\author{
Ji-Hwan Kim', Ja Young Kim', Seung-Sup Kim ${ }^{1,2}$ \\ ${ }^{1}$ Department of Public Health Sciences, Graduate School of Korea University, Seoul; ${ }^{2}$ School of Health Policy and Management, Korea University \\ College of Health Sciences, Seoul, Korea
}

Objectives: In South Korea (hereafter Korea), the number of adolescent offspring of immigrants has rapidly increased since the early 1990s, mainly due to international marriage. This research sought to examine the association between the experience of school violence and mental health outcomes, and the role of help-seeking behaviors in the association, among biethnic adolescents in Korea. Methods: We analyzed cross-sectional data of 3627 biethnic adolescents in Korea from the 2012 National Survey of Multicultural Families. Based on the victim's help-seeking behavior, adolescents who experienced school violence were classified into three groups: 'seeking help' group; 'feeling nothing' group; 'not seeking help' group. Multivariate logistic regression was applied to examine the associations between the experience of school violence and depressive symptoms for males and females separately.

Results: In the gender-stratified analysis, school violence was associated with depressive symptoms in the 'not seeking help' (odds ratio [OR], $7.05 ; 95 \%$ confidence interval [Cl], 3.76 to 13.23 ) and the 'seeking help' group (OR, 2.77; $95 \% \mathrm{Cl}, 1.73$ to 4.44 ) among male adolescents after adjusting for potential confounders, including the nationality of the immigrant parent and Korean language fluency. Similar associations were observed in the female groups. However, in the 'feeling nothing' group, the association was only significant for males (OR, 8.34; $95 \% \mathrm{Cl}, 2.82$ to 24.69$)$, but not females ( $\mathrm{OR}, 0.77 ; 95 \% \mathrm{Cl}, 0.18$ to 3.28 ).

Conclusions: This study suggests that experience of school violence is associated with depressive symptoms and that the role of victims' help-seeking behaviors in the association may differ by gender among biethnic adolescents in Korea.

Key words: Minority health, Bullying, Depression, Help-seeking behavior, Republic of Korea

Received: November 5, 2015 Accepted: January 11, 2016

Corresponding author: Seung-Sup Kim, MD, ScD

145 Anam-ro, Seoungbuk-gu, Seoul 02841, Korea

Tel: +82-2-3290-5676, Fax: +82-2-940-2870

E-mail: ssk3@korea.ac.kr

This is an Open Access article distributed under the terms of the Creative Commons Attribution Non-Commercial License (http://creativecommons.org/licenses/bync/3.0// which permits unrestricted non-commercial use, distribution, and reproduction in any medium, provided the original work is properly cited.

\section{INTRODUCTION}

South Korea (hereafter Korea) has traditionally been regarded as a ethnically homogenous society. However, the number of immigrants has increased since the early 1990s, largely due to international marriage. The proportion of foreign brides, mainly from China, Vietnam, and the Philippines, increased from 1\% in 1991 to approximately 8\% in 2011 [1]. Accordingly, the number of adolescent offspring of immigrants in Korea has grown rapidly, from 9389 in 2006 to 67806 in 2014, corre- 
sponding to $1.1 \%$ of the adolescent population in Korea [2].

Despite the increasing number of adolescent offspring of marriage migrants or naturalized Koreans (hereafter biethnic adolescents), little is known about their school experiences and health conditions in Korea. Biethnic adolescents could be vulnerable to school violence because ethnic differences have been reported to increase the risk of school violence [3-5]. This could be particularly true in Korea, considering that Korea has been reported to have strong intolerance towards people with different ethnicities [6,7].

A growing body of research indicates that school violence is associated with a higher risk of mental illness among adolescents. Since adolescents tend to rely on peers as a source of emotional support [8], experience of school violence from peers is likely to play a major role in shaping the mental health of an adolescent. Studies have reported that experiencing school violence is a significant risk factor for a variety of mental illnesses, including anxiety [9], depression [9-14], suicidal ideation [14], psychosis [15], and other psychiatric disorders [16,17].

Previous studies have suggested that gender differences may exist in the response of adolescents to the experience of school violence $[18,19]$. For example, Eschenbeck et al. [19] reported that female adolescents are more likely to seek help from others in stressful situations, whereas male adolescents may prefer to avoid dealing with stressful events. This difference could be important in examining the association between school violence and adolescent health outcomes, because help-seeking behavior is known to attenuate the impact of school violence [20].

However, to our knowledge, no previous research has examined the role of victims' help-seeking behaviors in the associations between school violence and health among biethnic adolescents in Korea separately for males and females. Therefore, we analyzed the 2012 National Survey of Multicultural Families (NSMF), a nationally representative dataset among marriage migrants or naturalized Koreans, their Korean spouses, and their adolescent offspring in Korea. Our analysis sought to answer the following questions:

1. What is the association between the experience of school violence and depressive symptoms among biethnic adolescents in Korea?

2. How does the association between the experience of school violence and depressive symptoms differ by victims' help-seeking behavior? Does this association vary by gender?

\section{METHODS}

\section{Participants}

This study analyzed the dataset from the 2012 NSMF, which was led by the Ministry of Gender Equality and Family and Statistics Korea. The target population of the survey was multicultural families, which were defined as containing ethnically heterogeneous members including marriage migrants or naturalized Koreans. The data were collected during July 2012 using two-step sampling. In the first step, 850 districts were randomly selected by considering the proportion of multicultural families among the 3470 total administrative districts that included more than one multicultural family. Then, based on the level of administrative district (urban/rural) and 17 nationalities, 26098 families were selected from 71933 multicultural families in the 850 administrative districts. Among those 26098 families, 19646 were successfully contacted and qualified as the study population. Of the families initially included in the sample, 15341 completed the survey interview (response rate $=78.1 \%$ ). Consequently, a total of 15341 families were recruited, including marriage migrants or naturalized Koreans $(n=15001)$, their Korean spouses $(n=13859)$, and their adolescent offspring $(n=4775)$. This dataset referred to the adolescent offspring as biethnic adolescents because one of their parents was Korean and the other was a foreigner or naturalized Korean. Following the Korean definition in the "Framework Act on Juveniles", an adolescent was defined as a person 9 to 24 years of age. Trained personnel collected data through in-person interviews. The present study drew upon the data pertaining to biethnic adolescents in mixed-ethnicity households $(n=4775)$. After removing data with missing values either for school violence or for any covariates, the sample size was 3627. The 2012 NSMF is publicly available through the Korea Women's Development Institute (http://eng.kwdi.re.kr/), and the data was anonymized and de-identified prior to public release. This study received institutional review board review exemption from the Korea University Institutional Review Board.

\section{Measures}

\section{School violence}

Experiences of school violence were measured using the yes/no question, "During the past 12 months, have you ever experienced school violence?" Adolescents who answered yes were required to answer the multiple-choice question, "How 
did you react when you experienced school violence?" Adolescents could choose among the following answers: a) talked to a teacher; b) talked to parents; $c$ ) reported the violence to the school website; d) called the police; e) discussed it with friends; f) thought it unfair, but endured it; and g) felt nothing and did not take any action. These responses were classified into three categories: (1) 'seeking help', indicating that the victim sought help from other people (a, b, c, d, e); (2) 'feeling nothing', referring to situations in which the victim did not feel uncomfortable and did not seek help from others (f); and (3) 'not seeking help', indicating that the victim felt uncomfortable but did not seek help from others $(g)$.

\section{Depressive symptoms}

Depressive symptoms were measured with the scaled question, "During the past 12 months, did you ever feel so sad or hopeless almost every day for two weeks or more in a row that you stopped doing your usual activities?" Respondents answered the question on a four-point scale, ranging from 1 (never) to 4 (often), and the answers were dichotomized (no depressive symptoms $=1$; depressive symptoms $=2,3$, or 4 ). This measure has been used in previous studies [14, 21].

\section{Covariates}

We first selected demographic and socioeconomic covariates. The demographic covariates of gender, age, education level, and residential area were included. Age was coded into four categories (9-11, 12-14, 15-17, and 18-24 years old), corresponding to classifications used in the educational system in Korea. Education levels were classified into three categories: elementary school, middle school, and high school. Residential area was coded as a dichotomous variable (urban vs. rural). The socioeconomic covariates of monthly household income and the education level of the Korean parent were included. Monthly household income was classified into five categories: $<1.00$ million Korean won (KRW), 1.00-1.99 million KRW, 2.002.99 million $K R W, 3.00-3.99$ million $K R W$, and $\geq 4.00$ million KRW. The education level of the Korean parent was coded into three categories: junior high school graduate or less, high school graduate, and college graduate or higher.

In addition, we selected three covariates that could potentially be associated with the experience of school violence as well as depressive symptoms among biethnic adolescents in Korea. First, the nationality of the immigrant parent was assessed based on their country of origin and/or self-reported ethnicity: China, Chinese-Koreans, Taiwan, Hong-Kong, Japan, Mongol, Vietnam, Philippines, Thailand, Cambodia, Uzbekistan, other countries in Southeast Asia or South Asia, Russia, Europe, Oceania, US, Canada, and others. Second, Korean language fluency in four different domains (speaking, listening, reading, and writing) was assessed on a scale from 1 (very good) to 5 (very poor). We summed the scores from each domain and divided that score into three categories: fluent (4), fair (5 to 7), and good (8 to 20). Third, experiences of discrimination were measured with the yes/no question, "Have you ever experienced discrimination because you are from a mixed-ethnicity family?"

\section{Statistical Analysis}

Logistic regression was used to investigate how experience of school violence was related to depressive symptoms and how this association differed by victims' help-seeking behavior and gender among the adolescent offspring of immigrants in Korea. Since the depressive symptoms of adolescents from the same household were likely to be correlated with each other, we used the Huber-White sandwich estimator to calculate odds ratios (ORs) and confidence intervals (Cls) robust to within-family clustering [22]. All covariates were included in the analysis as categorical variables. The results were expressed as ORs with $95 \% \mathrm{Cls}$. All analyses were performed with Stata/SE version 13.0 (Stata Corp., College Station, TX, USA).

\section{RESULTS}

As shown in Table 1, the prevalence of school violence was higher among younger adolescents who had lower education levels and Korean language fluency and who had experienced discrimination. Depressive symptoms were more common among older adolescents who had experienced discrimination, had a higher education level, and had poor fluency in Korean.

Table 2 presented the prevalence of the various types of school violence by gender, which was measured by using 8 categories: verbal assault (threats or abuse), group bullying, forced errands, robbery, physical abuse (slapping, kicking, beating, or locking in a certain place), sexual harassment, cyberbullying (via internet chatting, e-mail, or mobile phone), and others. The most common types of school violence experienced by male adolescents were verbal assault $(n=114,66.3 \%)$, group bullying $(n=44,25.6 \%)$, physical abuse $(n=38,22.1 \%)$, and robbery $(n=37,21.5 \%)$, whereas female adolescents most commonly 
Table 1. Sociodemographic distribution of the study population, depressive symptoms, and the experience of school violence by key covariates among biethnic adolescents in South Korea, from the 2012 National Survey of Multicultural Families $(n=3627)$

\begin{tabular}{|c|c|c|c|c|c|}
\hline & Distribution & $\begin{array}{c}\text { Prevalence of } \\
\text { depressive symptoms }\end{array}$ & $p$-value ${ }^{1}$ & $\begin{array}{l}\text { Experience of } \\
\text { school violence }\end{array}$ & $p$-value ${ }^{1}$ \\
\hline Gender & & & 0.075 & & 0.07 \\
\hline Male & $1911(52.7)$ & $390(20.4)$ & & $172(9.0)$ & \\
\hline Female & $1716(47.3)$ & $392(22.8)$ & & $126(7.3)$ & \\
\hline Age (y) & & & $<0.001$ & & $<0.001$ \\
\hline $9-11$ & $1706(47.0)$ & $293(17.2)$ & & $166(9.7)$ & \\
\hline $15-17$ & $616(17.0)$ & $190(30.8)$ & & $30(4.9)$ & \\
\hline $18-24$ & $87(2.4)$ & $23(26.4)$ & & $4(4.6)$ & \\
\hline Education level & & & $<0.001$ & & $<0.001$ \\
\hline Elementary school & $1950(53.8)$ & $348(17.9)$ & & $183(9.4)$ & \\
\hline Middle school & $1138(31.4)$ & $274(24.1)$ & & $92(8.1)$ & \\
\hline Rural & $1,476(40.7)$ & $303(20.5)$ & & $109(7.4)$ & \\
\hline Monthly household income ( $10^{4}$ Korean won) & & & 0.07 & & 0.10 \\
\hline$<100$ & $254(7.0)$ & $67(26.4)$ & & $27(10.6)$ & \\
\hline 100-199 & $930(25.6)$ & $205(22.0)$ & & $87(9.4)$ & \\
\hline $200-299$ & $1156(31.9)$ & $261(22.6)$ & & $96(8.3)$ & \\
\hline 300-399 & $690(19.0)$ & $139(20.1)$ & & $52(7.5)$ & \\
\hline$\geq 400$ & $597(16.5)$ & $110(18.4)$ & & $36(6.0)$ & \\
\hline Education level of the Korean parent & & & 0.67 & & 0.33 \\
\hline$\leq$ Junior high school graduate & $887(24.5)$ & $196(22.1)$ & & $83(9.4)$ & \\
\hline High school graduate & $1834(50.6)$ & $400(21.8)$ & & $141(7.7)$ & \\
\hline No & $3160(87.1)$ & $580(18.4)$ & & $133(4.2)$ & \\
\hline Yes & $467(12.9)$ & $202(43.3)$ & & $165(35.3)$ & \\
\hline
\end{tabular}

Values are presented as number (\%).

The distribution of the nationalities of the immigrant parents is not shown in this table.

${ }^{1} p$-value were calculated using the chi-square test, comparing the prevalence of depressive symptoms and school violence across different groups.

experienced verbal assault $(n=88,69.8 \%)$ and group bullying $(n=52,41.3 \%)$.

After adjusting for potential confounders, including the nationality of the immigrant parent and Korean language fluency, school violence was found to be significantly related to depressive symptoms in biethnic adolescents in Korea (Table 3). In comparison to biethnic adolescents who did not experience school violence, significant associations between school violence and depressive symptoms were found in each victim group with different help-seeking behaviors:'not seeking help' (OR, 7.33; $95 \% \mathrm{Cl}, 4.44$ to 12.10$)$, 'seeking help' (OR, 3.42; 95\% $\mathrm{Cl}, 2.42$ to 4.83 ), and 'feeling nothing' (OR, 3.85; $95 \% \mathrm{Cl}, 1.61$ to 9.18). Among male biethnic adolescents, school violence was significantly associated with depressive symptoms in the 'not seeking help' group (OR, 7.05; 95\% $\mathrm{Cl}, 3.76$ to 13.23$)$ and the 'seeking help' group (OR, 2.77; $95 \% \mathrm{Cl}, 1.73$ to 4.44$)$ after adjusting for potential confounders, including the nationality of the immigrant parent and Korean language fluency. Similar associ- 
ations were observed among the female 'not seeking help' (OR, $8.28 ; 95 \% \mathrm{Cl}, 3.53$ to 19.43$)$ and 'seeking help' $(\mathrm{OR}, 4.58 ; 95 \% \mathrm{Cl}$, 2.73 to 7.69 ) groups. In the 'feeling nothing' group, the associa-

Table 2. Types of school violence by gender among biethnic adolescents in South Korea, from the 2012 National Survey of Multicultural Families

\begin{tabular}{lcc}
\hline Type of school violence & Male & Female \\
\hline Verbal assault & $114(66.3)$ & $88(69.8)$ \\
Group bullying & $44(25.6)$ & $52(41.3)$ \\
Forced errands & $17(9.9)$ & $7(5.6)$ \\
Robbery & $37(21.5)$ & $13(10.3)$ \\
Physical abuse & $38(22.1)$ & $14(11.1)$ \\
Sexual harassment & $8(4.7)$ & $2(1.6)$ \\
Cyberbullying & $14(8.1)$ & $12(9.5)$ \\
Others & $3(1.7)$ & $2(1.6)$ \\
No. of victims (total) & 172 & 126
\end{tabular}

Values are presented as number (\%).

Since the victims were allowed to report more than one type of school violence, the sum of the percentages in each column may add up to over $100 \%$. tion was significant for males (OR, 8.34; $95 \% \mathrm{Cl}, 2.82$ to 24.69$)$ but not females (OR, $0.77 ; 95 \% \mathrm{Cl}, 0.18$ to 3.28$)$.

\section{DISCUSSION}

This study found that biethnic adolescents in Korea who had experienced school violence were more likely to have depressive symptoms after adjusting for covariates, including the nationality of the immigrant parent, Korean language fluency, and sociodemographic variables. These results are consistent with those of previous studies from other countries, including Ghana, Finland, and the United Kingdom [9-14]. A study conducted in Ghana found that victims of school violence were significantly more likely to report depressive symptoms, after adjusting for gender, age, and grade [14].

We also found that the association between school violence and depressive symptoms varied based on the victims' helpseeking behavior. A stronger association was observed when

Table 3. The gender-specific roles of help-seeking behaviors in the association between school violence and depressive symptoms among biethnic adolescents in South Korea, from the 2012 National Survey of Multicultural Families $(n=3627)$

\begin{tabular}{|c|c|c|c|c|c|c|}
\hline \multirow{2}{*}{ School violence } & \multirow{2}{*}{$\begin{array}{c}\text { Distribution } \\
\mathbf{n}(\%)\end{array}$} & \multirow{2}{*}{$\begin{array}{c}\begin{array}{c}\text { Prevalence of } \\
\text { depressive symptoms }\end{array} \\
\mathbf{n}(\%)\end{array}$} & \multicolumn{2}{|c|}{ Unadjusted } & \multicolumn{2}{|c|}{ Adjusted $^{1}$} \\
\hline & & & OR & $95 \% \mathrm{Cl}$ & OR & $95 \% \mathrm{Cl}$ \\
\hline No & $3329(91.8)$ & $616(18.5)$ & 1.00 & Reference & 1.00 & Reference \\
\hline Yes & $298(8.2)$ & $166(55.7)$ & $5.54 * * *$ & $4.30,7.13$ & $4.28^{* * *}$ & $3.22,5.70$ \\
\hline \multicolumn{7}{|c|}{ Stratified by help-seeking behaviors } \\
\hline No & $3329(91.8)$ & $616(18.5)$ & 1.00 & Reference & 1.00 & Reference \\
\hline \multicolumn{7}{|l|}{ Yes } \\
\hline Feeling nothing & $24(0.7)$ & $12(50.0)$ & $4.40^{* * *}$ & $1.97,9.85$ & $3.85^{*}$ & $1.61,9.18$ \\
\hline Seeking help & $184(5.1)$ & $92(50.0)$ & $4.40^{* * *}$ & $3.22,6.03$ & $3.42^{* * *}$ & $2.42,4.83$ \\
\hline Not seeking & $90(2.5)$ & $62(68.9)$ & $9.75^{* * *}$ & $6.19,15.36$ & $7.33^{* * *}$ & $4.44,12.10$ \\
\hline \multicolumn{7}{|l|}{ Stratified by gender } \\
\hline \multicolumn{7}{|l|}{ Male $(n=1911)$} \\
\hline No & $1739(91.0)$ & $301(17.3)$ & 1.00 & Reference & 1.00 & Reference \\
\hline \multicolumn{7}{|l|}{ Yes } \\
\hline Feeling nothing & $16(0.8)$ & $10(62.5)$ & $7.96 * * *$ & $2.88,22.04$ & $8.34^{* * *}$ & $2.82,24.69$ \\
\hline Seeking help & $100(5.2)$ & 42 (42.0) & $3.46^{* * *}$ & $2.27,5.28$ & $2.77^{* * *}$ & $1.73,4.44$ \\
\hline Not seeking & $56(2.9)$ & 37 (66.1) & $9.30 * * *$ & $5.27,16.41$ & $7.05^{* * *}$ & $3.76,13.23$ \\
\hline \multicolumn{7}{|l|}{ Female $(n=1716)$} \\
\hline No & 1590 (92.7) & $315(19.8)$ & 1.00 & Reference & 1.00 & Reference \\
\hline \multicolumn{7}{|l|}{ Yes } \\
\hline Feeling nothing & $8(0.5)$ & $2(25.0)$ & 1.35 & $0.27,6.72$ & 0.77 & $0.18,3.28$ \\
\hline Seeking help & $84(4.9)$ & 50 (59.5) & $5.95^{* * *}$ & $3.77,9.39$ & $4.58^{* * *}$ & $2.73,7.69$ \\
\hline Not seeking & $34(2.0)$ & $25(73.5)$ & $11.24^{* * *}$ & $5.20,24.32$ & $8.28^{* * *}$ & $3.53,19.43$ \\
\hline
\end{tabular}

OR, odds ratio; $\mathrm{Cl}$, confidence interval.

${ }^{1}$ Adjusted for age, gender, education level, residential area, mean household income, the education level of the Korean parent, the nationality of the immigrant parent, Korean language fluency, and discriminatory experiences.

${ }^{*} p<0.05,{ }^{* * *} p<0.001$. 
victims felt uncomfortable but did not seek help from others than in victims who sought help. This could be explained in several ways. First, this finding is consistent with a previous study reporting that adolescents who did not seek any help had a higher risk of depressive symptoms, whereas seeking help from others predicted a lower risk [23]. Seeking help from others could buffer the risk of depressive symptoms by strengthening adolescents' resources to cope with stressful life events [20]. Second, some adolescents who experience school violence are likely to blame themselves instead of attributing those experiences to external sources, possibly leading not to seek help from others. This pattern of internal blame makes victims of school violence more vulnerable to depressive symptoms [24,25].

More attention should be paid to how prevalence of depressive symptoms is different between genders for victims who reported feeling nothing. Our study found that depressive symptoms were more common among only male victims who reported feeling nothing about school violence compared to other groups. Previous studies have called this 'feeling nothing' reaction distancing, which means coping with negative emotions by reconstructing stressful events (e.g., "Tell myself it doesn't matter" or "Say I don't care") [26]. Kochenderfe-Ladd and Skinner [25] reported that victims who displayed cognitive distancing had a higher risk of anxiety than adolescents who did not experience school violence. This is consistent with our findings among male victims, but not among female victims.

Furthermore, previous studies have reported that men consider themselves problem-solvers because male socialization is based on the values of independence and suppression, rather than dependence and emotional expression [27]. Male victims might hide their feelings about school violence and report that they felt nothing uncomfortable because they do not want to be considered a weak person who failed to successfully complete the male socialization process. Along that line, male victims who reported 'feeling nothing' may have been working hard to satisfy this norm of socialization without seeking help from others, leading to a higher risk of depressive symptoms. This could explain why the male 'feeling nothing' group had the highest OR of depressive symptoms, whereas the corresponding female group did not. However, future studies should further explore this gender difference in coping strategies and its association with health $[19,28]$.

This study has several limitations. First, due to the cross-sectional design of the study, we could not rule out the potential reverse causation, which would mean that biethnic adoles- cents with depressive symptoms would have been more likely to experience school violence. A previous study with a longitudinal dataset reported that psychopathologic behavior is a consequence, rather than a cause, of bullying experiences among middle school students in Korea [29]. This kind of prospective study needs to be replicated among biethnic adolescents. Second, we should be cautious about interpreting gender differences in the association between school violence and depressive symptoms among the 'feeling nothing' group because the sample size was small (16 males and 8 females). Further studies with a larger sample size are necessary to examine this association in the 'feeling nothing' group.

Conversely, this study has several strengths that should be noted. The study population was a nationally representative sample of biethnic adolescents in Korea. The sample represented approximately $7 \%$ of the total biethnic adolescent population in Korea, enabling us to explore gender-specific associations between school violence and depressive symptoms by victims' help-seeking behaviors. Moreover, we were able to examine associations between school violence and depressive symptoms after adjusting for important potential confounders, including Korean language fluency, discriminatory experiences, and sociodemographic and socioeconomic variables.

To our knowledge, this is the first report of associations between the experience of school violence and health outcomes among biethnic adolescents in Korea. This study suggests that experience of school violence is associated with depressive symptoms and that the role of victims' help-seeking behaviors in this association may differ by gender among the biethnic adolescent in Korea.

\section{ACKNOWLEDGEMENTS}

This work was supported by the National Research Foundation of Korea grant funded by the Korean Government (NRF2014-S1A5A8016626).

\section{CONFLICT OF INTEREST}

The authors have no conflicts of interest associated with the material presented in this paper.

\section{ORCID}

Ji-Hwan Kim https://orcid.org/0000-0001-9424-5962 
Ja Young Kim https://orcid.org/0000-0002-8949-1912

Seung-Sup Kim http://orcid.org/0000-0003-1830-0282

\section{REFERENCES}

1. Korean Statistical Information Service. Vital statistics 19912011 [cited 2016 Jan 20]. Available from: http://www.index. go.kr/potal/main/EachDtlPageDetail.do?idx_cd=2430. \%EC\%97\%90\%EC\%84\%9C (Korean).

2. Statistics Korea. Adolescent statistics 2015 [cited 2016 Jan 20]. Available from: http://kostat.go.kr/portal/korea/kor_nw/2/1/ index.board?bmode $=$ read\&aSeq $=335384$ (Korean).

3. Graham S. Peer victimization in school exploring the ethnic context. Curr Dir Psychol Sci 2006;15(6):317-321.

4. Fitzpatrick KM, Dulin A, Piko B. Bullying and depressive symptomatology among low-income, African-American youth. J Youth Adolesc 2010;39(6):634-645.

5. O'Keefe M, Sela-Amit M. An examination of the effects of race/ethnicity and social class on adolescent's exposure to violence. J Soc Serv Res 1997;22(3):53-71.

6. World Values Survey. Integrated values surveys 1981-2014 [cited 2016 Jan 10]. Available from: http://www.worldvaluessurvey.org/WVSContents.jsp?CMSID=intinfo.

7. Kim Y, Son I, Kim SS. Association between discrimination and self-rated health among marriage migrants in South Korea: focusing on region of origin and gender differences. Health Soc Welf Rev 2015;35(3):421-452 (Korean).

8. Hartup WW. The company they keep: friendships and their developmental significance. Child Dev 1996;67(1):1-13.

9. Bond L, Carlin JB, Thomas L, Rubin K, Patton G. Does bullying cause emotional problems? A prospective study of young teenagers. BMJ 2001;323(7311):480-484.

10. Kaltiala-Heino R, Fröjd S, Marttunen M. Involvement in bullying and depression in a 2-year follow-up in middle adolescence. Eur Child Adolesc Psychiatry 2010;19(1):45-55.

11. Klomek AB, Sourander A, Kumpulainen $K$, Piha J, Tamminen T, Moilanen I, et al. Childhood bullying as a risk for later depression and suicidal ideation among Finnish males. J Affect Disord 2008;109(1-2):47-55.

12. Kaltiala-Heino R, Rimpelä M, Marttunen M, Rimpelä A, Rantanen P. Bullying, depression, and suicidal ideation in Finnish adolescents: school survey. BMJ 1999;319(7206):348-351.

13. Ranta K, Kaltiala-Heino R, Pelkonen M, Marttunen M. Associations between peer victimization, self-reported depression and social phobia among adolescents: the role of comorbidi- ty. J Adolesc 2009;32(1):77-93.

14. Owusu A, Hart P, Oliver B, Kang M. The association between bullying and psychological health among senior high school students in Ghana, West Africa. J Sch Health 2011;81(5):231238.

15. Schreier A, Wolke D, Thomas K, Horwood J, Hollis C, Gunnell D, et al. Prospective study of peer victimization in childhood and psychotic symptoms in a nonclinical population at age 12 years. Arch Gen Psychiatry 2009;66(5):527-536.

16. Sourander A, Jensen $P$, Rönning JA, Niemelä $S$, Helenius $H$, Sillanmäki $L$, et al. What is the early adulthood outcome of boys who bully or are bullied in childhood? The Finnish "From a Boy to a Man" study. Pediatrics 2007;120(2):397-404.

17. Sourander A, Ronning J, Brunstein-Klomek A, Gyllenberg D, Kumpulainen K, Niemelä S, et al. Childhood bullying behavior and later psychiatric hospital and psychopharmacologic treatment: findings from the Finnish 1981 birth cohort study. Arch Gen Psychiatry 2009;66(9):1005-1012.

18. Barker G. Adolescents, social support and help-seeking behaviour. Geneva: World Health Organization; 2007, p. 10-11

19. Eschenbeck H, Kohlmann CW, Lohaus A. Gender differences in coping strategies in children and adolescents. J Individ Differ 2007;28(1):18-26.

20. Cheng ST, Cheung KC, Cheung CK. Peer victimization and depression among Hong Kong adolescents. J Clin Psychol 2008;64(6):766-776.

21. Eaton DK, Kann L, Kinchen S, Shanklin S, Flint KH, Hawkins J, et al. Youth risk behavior surveillance-United States, 2011. MMWR Surveill Summ 2012;61(4):1-162.

22. Rogers W. Regression standard errors in clustered samples. Stata Tech Bull 1994;3(13):19-23.

23. Machmutow K, Perren S, Sticca F, Alsaker FD. Peer victimisation and depressive symptoms: can specific coping strategies buffer the negative impact of cybervictimisation? Emot Behav Diffic 2012;17(3-4):403-420.

24. Taylor KA, Sullivan TN, Kliewer W. A longitudinal path analysis of peer victimization, threat appraisals to the self, and aggression, anxiety, and depression among urban African American adolescents. J Youth Adolesc 2013;42(2):178-189.

25. Kochenderfer-Ladd B, Skinner K. Children's coping strategies: moderators of the effects of peer victimization? Dev Psychol 2002;38(2):267-278.

26. Causey DL, Dubow EF. Development of a self-report coping measure for elementary school children. J Clin Child Psychol 1992;21(1):47-59. 
27. Grinstein-Weiss M, Fishman G, Eisikovits Z. Gender and ethnic differences in formal and informal help seeking among Israeli adolescents. J Adolesc 2005;28(6):765-779.

28. Broderick PC. Early adolescent gender differences in the use of ruminative and distracting coping strategies. J Early Ado- lesc 1998;18(2):173-191.

29. Kim YS, Leventhal BL, Koh YJ, Hubbard A, Boyce WT. School bullying and youth violence: causes or consequences of psychopathologic behavior? Arch Gen Psychiatry 2006;63(9): 1035-1041. 